\title{
RAMS Analysis of Train Air Braking System Based on GO-Bayes Method and Big Data Platform
}

\author{
Guoqiang Cai $\mathbb{D}^{1,2}$ Yaofei Wang, ${ }^{1,3}$ Qiong Song, ${ }^{1,2}$ and Chen Yang ${ }^{4}$ \\ ${ }^{1}$ State Key Lab of Rail Traffic Control \& Safety, Beijing Jiaotong University, Beijing 100044, China \\ ${ }^{2}$ School of Traffic and Transportation, Beijing Jiaotong University, Beijing 100044, China \\ ${ }^{3}$ School of Electronic and Information Engineering, Beijing Jiaotong University, Beijing 100044, China \\ ${ }^{4}$ Institute of Computing Technologies, China Academy of Railway Sciences, Beijing 100081, China \\ Correspondence should be addressed to Guoqiang Cai; gqcai@bjtu.edu.cn
}

Received 11 June 2018; Accepted 27 August 2018; Published 14 October 2018

Academic Editor: Zhihan Lv

Copyright (C) 2018 Guoqiang Cai et al. This is an open access article distributed under the Creative Commons Attribution License, which permits unrestricted use, distribution, and reproduction in any medium, provided the original work is properly cited.

\begin{abstract}
The RAMS (reliability, availability, maintainability, and security) of the air braking system is an important indicator to measure the safety performance of the system; it can reduce the life cycle cost (LCC) of the rail transit system. Existing safety analysis methods are limited to the level of relatively simple factual descriptions and statistical induction, failing to provide a comprehensive safety evaluation on the basis of system structure and accumulated data. In this paper, a new method of safety analysis is described for the failure mode of the air braking system, GO-Bayes. This method combines the structural modeling of the GO method with the probabilistic reasoning of Bayes methods, introduces the probability into the analysis process of GO, performs reliability analysis of the air braking system, and builds a big data platform for the air braking system to guide the system maintenance strategy. An automatic train air braking system is taken as an example to verify the usefulness and accuracy of the proposed method. Using ExtendSim software shows the feasibility of the method and its advantages in comparison with fault tree analysis.
\end{abstract}

\section{Introduction}

Safety evaluation techniques of RAMS (reliability, availability, maintainability, and security) originated in the 1930s. As the awareness of the importance of safety has continued to grow, system safety engineering has become a mature discipline and has gradually been extended to the aviation, nuclear, petroleum, chemical, and general manufacturing industries. Many theories and methods have been proposed, such as safety checklists [1], safety analysis [2] and evaluation methods [3], event trees (ETs) [4], fault tree analysis (FTA) [5] and risk assessment techniques [6], mode evaluation, human factor analysis and classification system (HFACS) applied on UK rail safety [7], six-stage safety and other risk index evaluation methods, and artificial neural networks.

In the field of rail transit, RAMS [8] is widely used to analyze the reliability of equipment operation. In 1986, Sweden issued the first requirement for the RAMS index in the invitation to purchase high-speed trains, requiring suppliers to make commitments for their reliability, maintainability, and safety, and ensure that all indicators meet the specified value after being put into operation. In the 1970s, the failure data of the Shinkansen was analyzed in Japan, and the reliability of the locomotive was improved by improving the design. TGV trains in France have strict requirements on RAMS during the design phase, and their maintenance costs are decreasing year by year. Kang et al. [9] made an evaluation of the smooth state of RAMS on the high-speed railway track. $\mathrm{Pu}[10]$ introduces RAMS to the urban rail train monitoring system. Chen $[11,12]$ analyzed the key elements of RAMS management in the rail transit industry. Cooper and Herskovits [13] present a Bayes method for constructing probabilistic networks and make a credibility evaluation of the system. Dobrivoje et al. [14] qualitatively analyze the fault tree of the hydraulic booster in the commercial vehicle steering system. Holmes and Mallick [15] proposed a Bayes analysis of the piecewise-linear model. Adjusting the data yields a Bayes local linear model with predictive and local linear parameter distributions. Sun [16] analyzed the RAMS control measures taken at various stages of the signal system. 
Yasuoka et al. [17] explain how to use RAMS for railway signal system management. Yang et al. [18] introduced the RAMS analysis of the high-speed railway power supply system. The GO method is widely used in the RAMS analysis of rail transit systems [18-21]; Huang et al. [22] apply RAMS to 9 electromechanical subsystems of Chengdu Rail transit line 1, but there are a few cases successfully used in air braking systems. Many scholars use the GO-FLOW method in the safety analysis of a high-speed railway [23-28]. Some scholars apply big data to the operation and management of rail transit to guide maintenance strategies [29-34].

In this paper, the GO-Bayes is proposed, its basic concepts are described systematically, structured bidirectional modeling, Bayes theory fusion, and various detection information, model-based inverse fault probability reasoning, and other method simulation using the Monte-Carlo method and through a subway transit air braking system example to verify its effectiveness and accuracy.

\section{Train Air Braking System}

Train air braking is also called a mechanical brake or friction brake. A complete brake system device consists of two parts: a brake control system and a brake actuation system. The brake control system consists of the brake signal generation and transmission device and the brake control device. The brake actuation system is usually called the basic brake device, with a brake shoe brake and a disc brake; there is no essential difference between them, and the way of modeling is the same; only the way of a working form is different. The system structure diagram is shown in Figure 1.

2.1. Basic Components of Air Braking System. A braking system's basic components include an air compressor and filtration device (as shown by A5 in the schematic diagram in Figure 2,1), a main duct, pneumatic suspension devices $(\mathrm{L} 1, \ldots)$, a braking airline and control system $(\mathrm{B} 1, \ldots$, including a parking braking device $\mathrm{B} 7$ and a braking control section $\mathrm{B} 13)$, main brakes $(\mathrm{C} 1, \ldots)$, and electronic antiskid devices $(\mathrm{G} 1, \ldots)$; the meaning of code letter is described in detail in Figure 3, 2.

The brake control system is composed of the following: A5, B2, B7.01, B15, B3.01, and L10-air feed and dust filtration device; B1, B5, B6, B11, B16, B19, B20, L3, L9, B7.02, and B7.07-stop valve; B8, B7.06, B13.04, B13.08, and B13.12-safety valve; U1 - safety lift device for pantograph; B7-parking brake control device; B9-bake tank; B10-air evacuation valve; B13-common/emergency braking control unit; L1 - pneumatic suspension devices; L5-pressure control valve; L6-hydrogen-oil differential pressure valve; L7-air spring; L8-dummy reservoir; G1-electronic antiskid devices; G2 - measure speed gears; G3-speed transmitter; $\mathrm{C} 1, \mathrm{C} 2$, and $\mathrm{C} 3$-air hose; $\mathrm{C} 4$ and $\mathrm{C} 5$-damper brake shoe; C6 and C7-common/emergency braking basic unit; C8-parking brake basic device; B7.03 - parking brake control magnetic valve; B7.04-double branch valve; $\mathrm{B} 7.05$ and B13.13 - air switch; B13.02 and B13.03 - common brake control magnetic valve; $\mathrm{B} 13.05, \mathrm{~B} 13.07$, and B13.11-pressure sensor; B13.06-brake relay valve; B13.09—empty and load

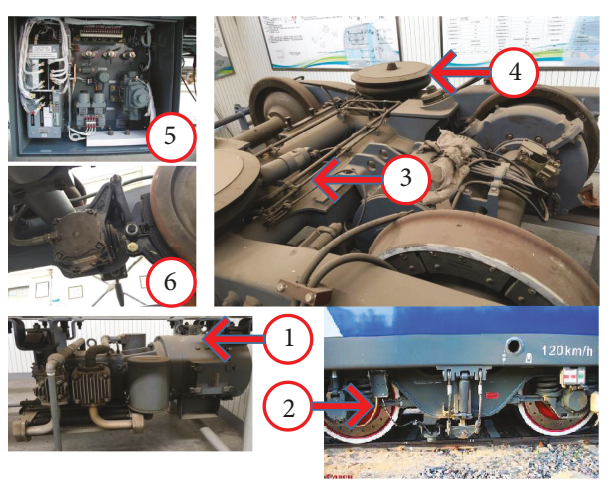

Figure 1: Air braking system structure. 1-air supply device, 2-brake air circuit, 3-air spring suspension, 4-brake control unit, 5-parking brake control device, and 6-basic brake device.

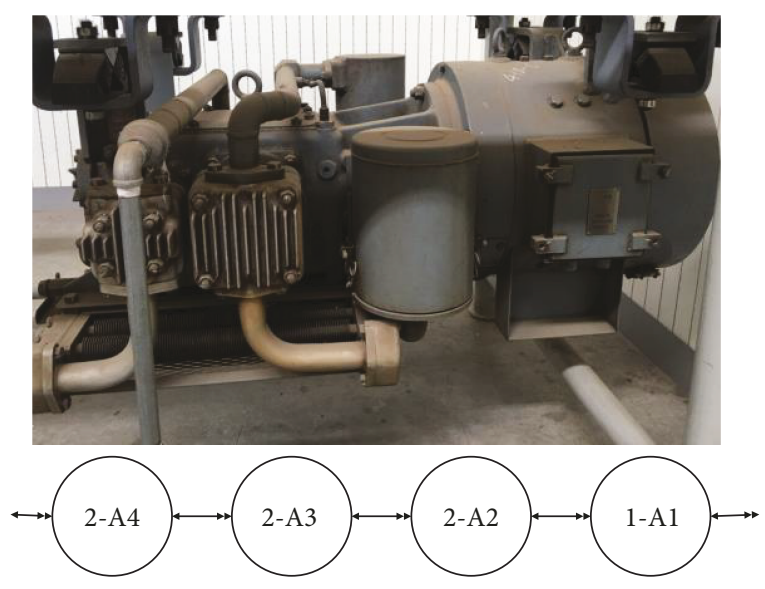

Figure 2: Model of the air supply device.

brake equipment; W1-linking equipment; and B13.10emergency braking control magnetic valve. A dotted box represents a function unit; a solid box represents a control cabinet, as shown in Figure 3.

2.2. Air Braking System Failure Modes. The air braking system is composed of a series of components; these components in the long-term use of the process will have varying degrees of failure, such as air compressor failure, drying tower gas leakage, and subway vehicles in the operation of these faults. Record it so you can look through the table to get the probability of different parts failing. The failure rate is calculated as follows:

$$
\text { Failure rate }=\frac{\text { times of failure }}{\text { total times }} \times 100 \% .
$$

In the process of urban rail transit train operation, the maintenance management system records the relevant fault date, fault description and processing results, and other information, as shown in Table 1.

2.3. Problems in Train Air Braking System Safety Analysis. As we all know, vehicles have the characteristics of high speed, large passenger capacity, and complicated environment. According to the Guangzhou Rail transit's operational 


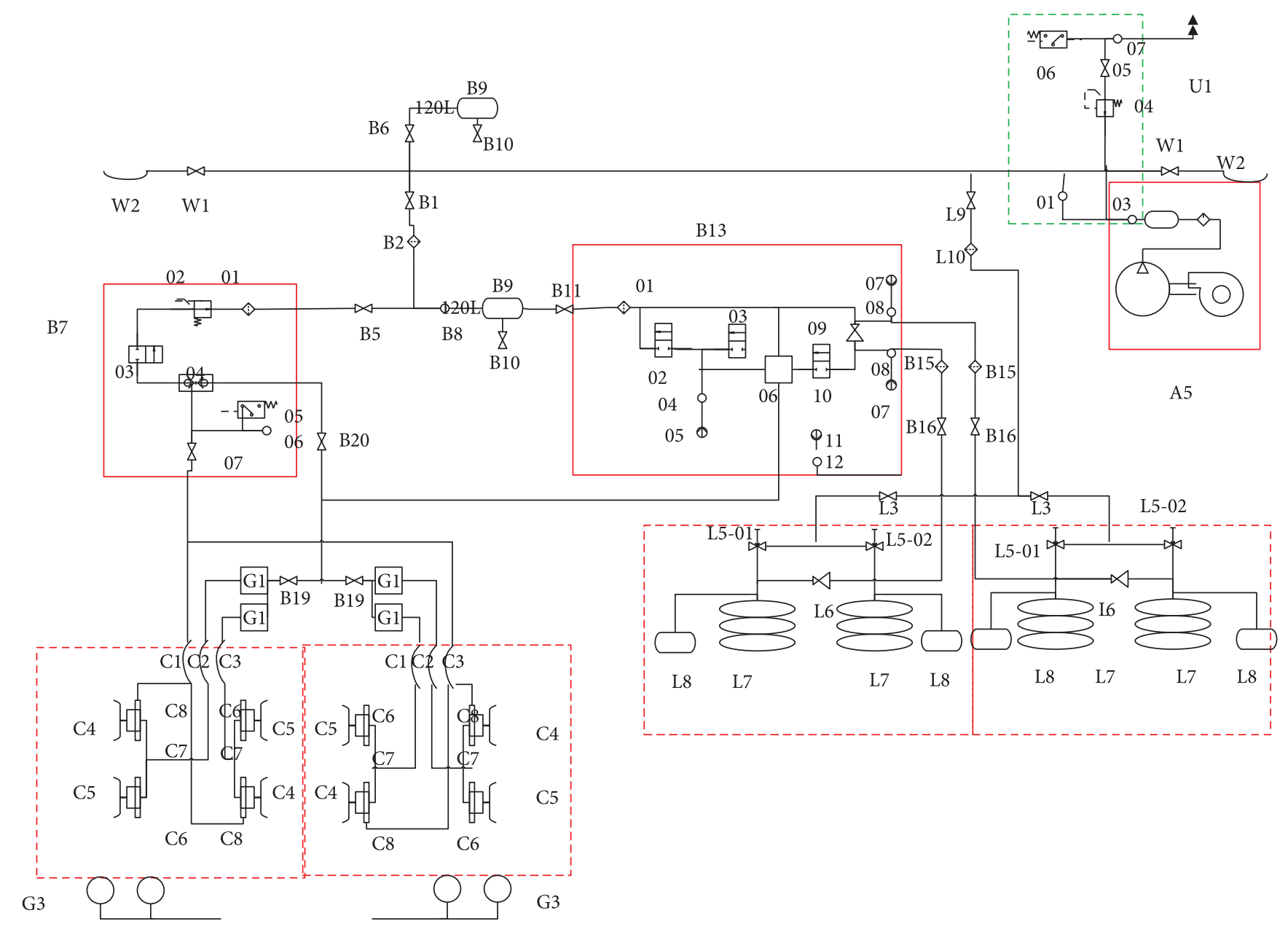

FIGURE 3: Schematic diagram of an urban rail transit vehicle air braking system.

TABLE 1: Guangzhou rail transit fault record.

\begin{tabular}{|c|c|c|}
\hline Date & Failure mode & Processing results \\
\hline $2008-1-620: 00$ & Air compressor failure & Software has been updated tracking \\
\hline $2008-1-268: 53$ & Dryer's leak & Dryer's leak \\
\hline $2008-2-1710: 50$ & Master cylinder fluctuations & Back to the library \\
\hline $2008-2-228: 15$ & Axis speed sensor failure & Change the speed sensor \\
\hline $2008-3-79: 43$ & One-axis motor speed sensor failure & Return to the library to check the vehicle, no exception \\
\hline 2008-3-23 1:00 & Air compressor filter failure & Change the filter \\
\hline $2008-4-228: 15$ & Safety valve leak & Replace the safety valve \\
\hline $2008-5-2415: 00$ & Emergency brake circuit relay failure & Replacing the relay \\
\hline 2008-6-3 $1: 22$ & ECU: 04.22 & Overhaul ECU: 04.22 \\
\hline $2008-6-271: 00$ & ECU: 31 & Overhaul ECU: 31 \\
\hline $2008-7-161: 20$ & Shaft brake cylinder failure & Replace shaft brake cylinder \\
\hline $2008-7-271: 00$ & 92022 triaxial brake cylinder connection pin prolapse & After the overhaul yard demolition, loading normal \\
\hline 2008-7-31 $1: 15$ & 0104\#92191, 92241 brake shoe wear exceeded & Replace 10 brake shoes \\
\hline
\end{tabular}

failure statistics, among the numerous breakdowns in the vehicle, the bogies (33.3\%) and the braking system (16.7\%) have the highest failure frequency. As the key equipment of the vehicle, the braking system itself has the characteristics of frequentness and complexity. Once a failure occurs, it will directly affect the operation of the vehicle, even cause vehicle accidents. At present, the safety assessment of the vehicle braking system mainly adopts some traditional analysis methods, including the safety inspection table method, prehazard analysis (PHA) analysis, event tree 
analysis (ETA), failure mode and consequence analysis (FMEA) method, and fault tree analysis (FTA) methods, which are still traditional qualitative, quantitative, and combined methods; they are only limited to a simpler factual description and statistical induction level, and it is difficult to achieve comprehensive safety assessment from the system structure and information level.

Therefore, this paper introduces the Go-Bayes method to the safety analysis of the air braking system and describes the massive fault information as a probabilistic meaning, which greatly simplifies the analysis workload. The Go system-based modeling structure and Bayes probability theory can realize information fusion and data-driven comprehensive security analysis methods and achieve more effective safety assessment.

\section{GO-Bayes Model of Air Braking System}

The GO-Bayes method is based on the fault of the system unit. It uses the basic unit model and logic module to establish the analysis model according to the system working principle diagram or flow chart and calculates the reliability probability parameters according to certain operation rules. At the same time, the Bayes method is used to carry out the real-time fault deduction of the system's security state and solve the reverse probability so as to realize the comprehensive evaluation of the system security. The GO-Bayes method is applied to the safety analysis of the train air braking system with the following innovative features:

(1) The structural features of the air braking system are modular, and the Go model inherited by the Go-Bayes method exactly meets the modeling requirements

(2) The development of state monitoring technology makes it possible to obtain more monitoring information, combining historical failure information and monitoring information effectively can better analyze the security state of the system, and the Bayes theory introduced by GO-Bayes method is the key method of information fusion

(3) When the system fails, we can combine the realtime status monitoring information and experiential knowledge to locate fault points based on probability. The Bayes theory is used to obtain the "reverse probability" and achieve quantitative and qualitative analysis. It has a practical significance for the safety analysis and fault detection of air braking systems

The GO-Bayes method inherits the GO model diagram (schematic, flow diagram, or engineering). Therefore, the basic operator of the GO method is used in the modeling process, as shown in Figure 4.

In the modeling process of the GO-Bayes method, firstly, the basic unit models are summarized and give a calculation of the units. Secondly, according to the system structure, the system model is built in the basic unit, and the units are connected in sequence. The original input data is calculated by the algorithm of all the units in the system model, and the success rate of the system output is obtained. Similarly, based on the results of the forward real-time assessment, the inverse probability inference is reintroduced to obtain real-time failure analysis results. The system adopts a hierarchical structure of modules; that is, the system is composed of subsystems, and the subsystem is composed of basic components; only input/output data interfaces and other control interfaces are provided. The air braking system is a large system with a complex structure and a large model structure. It is easy to read and manage with a hierarchical model, as shown in Figure 5:

The common unit models in the project are the series model, parallel model, and voting model. For discussion purposes, make the following assumptions:

(1) The system and unit have only two states: normal and faulty

(2) The normal and faults between each unit are independent

(3) Since some units are connected to other units through input and output ports, for example, air compressors have many components, but we only need to consider whether it can compress air normally. So these units can be modeled as a whole without considering the internal security status and connection of components

3.1. The GO-Bayes Model of Basic Units. The system adopts a hierarchical modeling structure and divides the braking system into six parts: air supply device, brake air circuit, air spring suspension, brake control unit, parking brake control device, and basic brake device. The detailed model of each basic unit is as follows. The meaning represented by the component number can be queried in Table 2:

(1) Air Supply Device. The drive motor drives the air compressor device to work. After the compressed air is dried by the drying tower, it is injected into the total air cylinder for storage, as shown in Figure 2

(2) Brake Gas Path. Compressed air is mainly transported through the main air duct of the train, and some shut-off valves, safety valves, etc. are required to ensure the circulation or cut-off of compressed air, as shown in Figure 6

(3) Air Spring Suspension. Compressed air is delivered to air spring air cylinders and air springs through stop valves, filters, etc. The left and right height of the vehicle body is adjusted by the height valve and differential pressure valve, and the pressure information is transmitted to the brake control unit, as shown in Figure 7

(4) Brake Control Device. The brake control device (BCU) is mainly connected to the compressed air delivered by the brake cylinder, the control command 


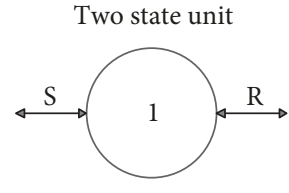

(i)

Multi signal generator

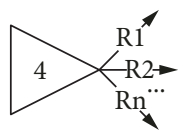

(iv)

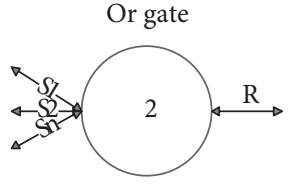

(ii)

Signal generator

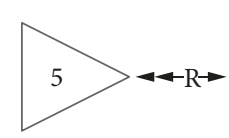

(v)

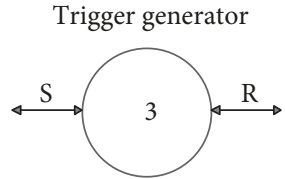

(iii)

Signal conduction element

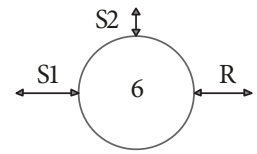

(vi)

Function operator

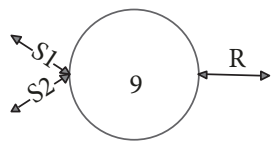

(ix)

AND gate

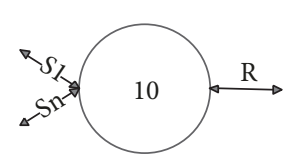

(x)

Multiple input/output device

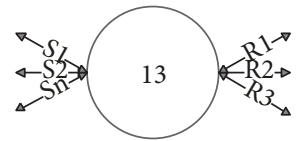

(xiii)

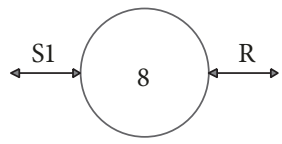

(viii)

" $\mathrm{m}$ " taking " $\mathrm{k}$ " gate

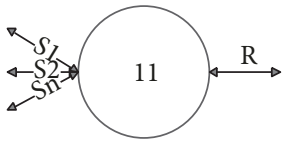

(xi)

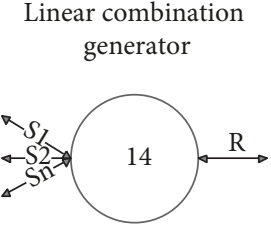

(xiv)

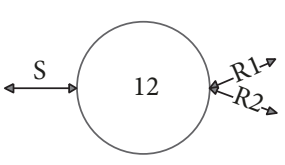

(xii)

Limiting probability gate

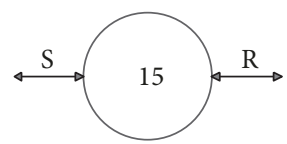

(xv)

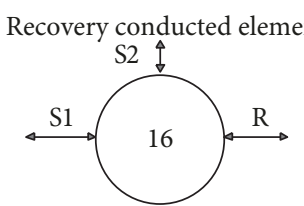

(xvi)

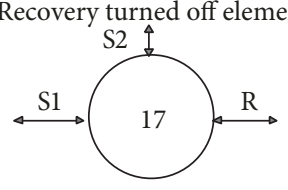

(xvii)

Figure 4: Basic operators of the GO method.

issued by the brake microprocessor control system (ECU), and the pressure of the air spring suspension device and so on. The control analog converter converts the control command to "precontrol air pressure" and controls the relay valve to output the brake cylinder after being restrained by the pressure switch and the weighing valve, as shown in Figure 8

(5) Parking Brake Control Device. The parking brake device is directly connected to the brake compressed air, and the parking brake solenoid valve and pulse valve are controlled by the parking brake instruction to prevent the vehicle from running, as shown in Figure 9
(6) Basic Braking Device. The basic braking device is an implementing part of the braking system; the compressed air is finally delivered to the brake air cylinder to push the brake shoe and the wheel to generate friction to complete the braking, as shown in Figure 10

In the establishment of the system GO-Bayes model, some units describe the object as a single component, and some units describe a set of functional devices, because the device and the internal parts of the low failure rate or failure data are not easy to obtain, such as air compressor, analog converter, ECU code, relay valve, cut-off valve, and parking braking solenoid valve. We will not list them one by one, 


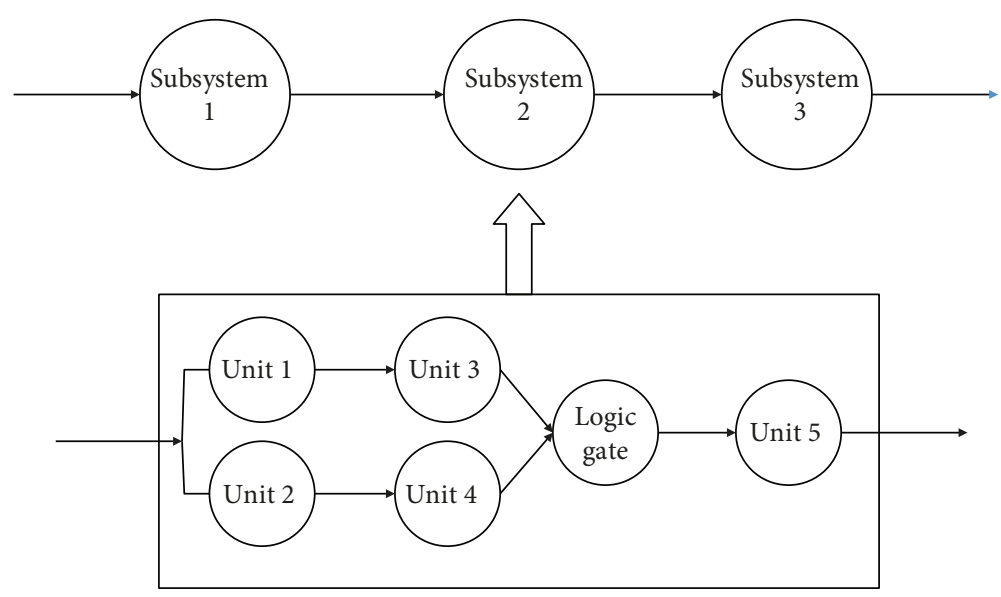

FIgURE 5: Hierarchical model.

TABLE 2: Components of the models in the air braking system.

\begin{tabular}{|c|c|c|c|c|c|}
\hline Model & Code & Corresponding component & Model & Code & Corresponding component \\
\hline \multirow{4}{*}{ Air supply device model } & 1-A1 & Drive motor & \multirow{16}{*}{$\begin{array}{c}\text { Pneumatic suspension } \\
\text { device model }\end{array}$} & $2-\mathrm{Cl}$ & Cut-off valve \\
\hline & 2-A2 & Air compressor & & $2-\mathrm{C} 2$ & Filter \\
\hline & $2-\mathrm{A} 3$ & Drying tower & & $2-\mathrm{C} 3$ & Air-spring cylinder \\
\hline & $2-\mathrm{A} 4$ & Main air cylinder & & $2-\mathrm{C} 4$ & Cut-off valve \\
\hline \multirow{5}{*}{ Braking air route model } & $2-\mathrm{B} 1$ & Main air duct & & $2-\mathrm{C} 5$ & Left height valve \\
\hline & $2-B 2$ & Cut-off valve & & $2-\mathrm{C} 6$ & Right height valve \\
\hline & $2-\mathrm{B} 3$ & Safety valve & & $2-\mathrm{C} 7$ & Air spring \\
\hline & $3-B 4$ & Braking reservoir cylinder & & $2-\mathrm{C} 8$ & Air spring \\
\hline & 1-B5 & Exhaust valve & & $3-\mathrm{C} 9$ & Pressure valve \\
\hline \multirow{7}{*}{ Inner braking control device } & 3-D1 & Analog converter & & $2-\mathrm{C} 10$ & Cut-off valve \\
\hline & 1-D2 & ECU code & & $2-\mathrm{C} 11$ & Left height valve \\
\hline & 2-D3 & Emergency solenoid valve & & $2-\mathrm{C} 12$ & Right height valve \\
\hline & 3-D4 & Pressure switch & & $2-\mathrm{C} 13$ & Air spring \\
\hline & 3-D5 & Weighing valve & & 2-C14 & Air spring \\
\hline & 3-D6 & OR gate & & $3-\mathrm{C} 15$ & Pressure valve \\
\hline & 3-D7 & Relay valve & & $1-\mathrm{E} 4$ & Parking braking code \\
\hline \multirow{3}{*}{ Parking braking device model } & $2-\mathrm{E} 1$ & Cut-off valve & \multirow{3}{*}{$\begin{array}{l}\text { Parking braking } \\
\text { device model }\end{array}$} & 3-E5 & Pulse valve \\
\hline & 2-E2 & Pressure switch & & 1-E6 & Two-way valve \\
\hline & 3-E3 & Parking braking solenoid valve & & 2-E7 & Check \\
\hline \multirow{12}{*}{ Main braking device model } & $2-\mathrm{F} 1$ & Cut-off valve & \multirow{12}{*}{$\begin{array}{l}\text { Main braking } \\
\text { device model }\end{array}$} & $1-\mathrm{F} 12$ & Speed sensor \\
\hline & 2-F2 & Cut-off valve & & $1-\mathrm{F} 13$ & Speed sensor \\
\hline & 3-F3 & Slip solenoid valve & & 1-F14 & Speed sensor \\
\hline & $3-\mathrm{F} 4$ & Slip solenoid valve & & 2-F15 & Slipper \\
\hline & 3-F5 & Slip solenoid valve & & 2-F16 & Slipper \\
\hline & 3-F6 & Slip solenoid valve & & 2-F17 & Slipper \\
\hline & 2-F7 & Braking air reservoir & & 2-F18 & Slipper \\
\hline & 2-F8 & Braking air reservoir & & 5-F19 & OR gate \\
\hline & \multirow{2}{*}{ 2-F9 } & \multirow{2}{*}{ Braking air reservoir } & & $5-\mathrm{F} 20$ & OR gate \\
\hline & & & & $5-\mathrm{F} 21$ & OR gate \\
\hline & 2-F10 & Braking air reservoir & & & \\
\hline & 2-F11 & Speed sensor & & & \\
\hline
\end{tabular}




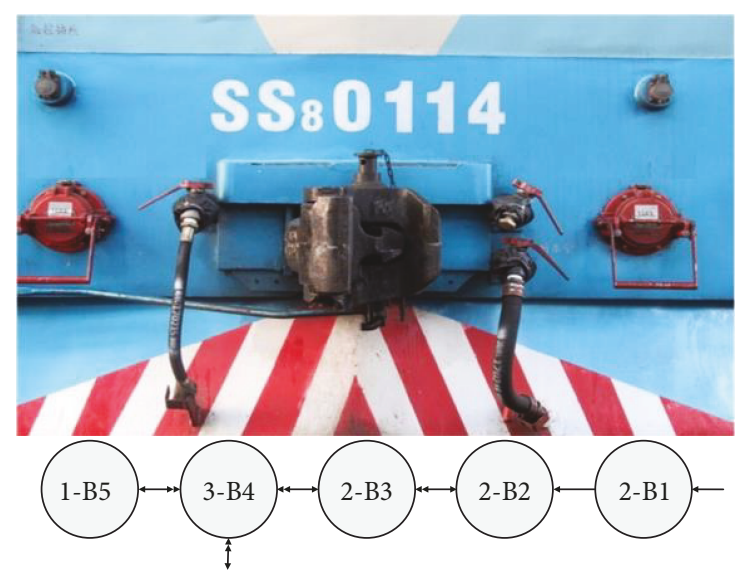

FIgURE 6: Model of brake gas path.

but their work effect is only related to the probability of success of the unit; we can simplify the modeling complexity of the whole system by means of unit modeling. Therefore, the modeling process should be based on the specific characteristics of the object system flexible modeling. Another feature of the use of hierarchical block modeling is that one of the modules can be analyzed separately in the use of analysis of the entire system analysis; of course, the entire system analysis must pay attention to the correlation between modules such as common signal processing.

3.2. The Processing Method of the Common Signal in the Model. In the system model, there is a unit output to two or more than two successive units to be merged as the input of subsequent units; then the input data is called common signal, as shown in Figure 11.

The existence of the common signal will cause high-order subitems in the forward channel of the system. The value of these probability subitems is very small, which will affect the accuracy of the analysis. Therefore, we must preprocess the common signal.

The output of single 1-1 is the input of 2-2, 2-3, and 2-4. When 2-3 and 2-4 are used as 5-5 inputs, when calculating the unreliability, two input signals contain 1-1 output data and need correction. The same is the case that 2-2 and 5-5 also contain 1-1 of the output data as the input of 5-6.

The processing method is when the common signal branches are reassembled, the reliability of unit 1-1 will appear two times and higher times and then replace two times and higher order items into one item.

Set up $R_{S(1-1)}=x_{1}, R_{S(2-2)}=x_{2}, R_{S(2-3)}=x_{3}$, and $R_{S(2-4)}=$ $x_{4}, x_{1}, x_{2}, x_{3}, x_{4} \epsilon(0,1)$; when calculating the 5-5 output, it consists of common signals:

$$
R_{o(5-5)}=R_{o(2-3)} R_{o(2-4)} .
$$

In the meanwhile,

$$
\begin{aligned}
& R_{o(2-3)}=R_{s(1-1)} R_{s(2-3)=} x_{1} x_{3}, \\
& R_{o(5-5)}=R_{o(2-3)} R_{o(2-4)=} x_{1} x_{4} .
\end{aligned}
$$

Obviously,

$$
R_{o(5-5)}=R_{o(2-3)} R_{o(2-4)}=\left[R_{S(1-1)}\right]^{2} R_{S(2-3)} R_{S(2-4)} .
$$

It consists of a square term $\left[R_{S(1-1)}\right]^{2}$; here, we replace $\left[R_{S(1-1)}\right]^{2}$ with $R_{S(1-1)}$, and the result is shown as follows:

$$
R_{o(5-5)}=R_{S(1-1)} R_{S(2-3)} R_{S(2-4)}=x_{1} x_{3} x_{4} .
$$

In the reverse fault probability inference, there is no need to deal with the common signal; that is to say, when the system comes to fault, $R_{I}(5-6)=1$, the reverse probability of unit 2-2 output signal is

$$
P_{I}(2-2)=\frac{F_{O}(2-2) \times 1}{F_{O}(5-6)}=\frac{1-X_{1} X_{2}}{1-X_{1} X_{2} X_{3} X_{4}} .
$$

The reverse probability of unit 5-5 output signal is

$$
P_{I}(5-5)=\frac{F_{O}(5-5) \times 1}{F_{O}(5-6)}=\frac{1-X_{1} X_{3} X_{4}}{1-X_{1} X_{2} X_{3} X_{4}} .
$$

The reverse probability of unit 2-2 itself is

$$
P_{S}(2-2)=\frac{F_{S}(2-2) P_{I}(2-2)}{F_{O}(2-2)}=\frac{1-X_{2}}{1-X_{1} X_{2} X_{3} X_{4}} .
$$

3.3. Calculation of Probability Indicators. Rail transits run continuously for a long time and are not easy to analyze. We can take the average processing method and average the fault events to the time unit of $100 \mathrm{H}$. Suppose a $100 \mathrm{H}$ steady running time, as shown in Table 3 . In the calculation process, $P(H \mid A)$ indicates the failure probability of units when the system fails, $P(\bar{H} \mid A)$ indicates the normal probability of units when the system fails, $P(H \mid \bar{A})$ indicates the failure probability of units when the system is normal, and $P$ $(\bar{H} \mid \bar{A})$ indicates the normal probability of units when the system is normal. According to Bayes' theorem, the posterior fault probability can be obtained as

$$
\begin{aligned}
P(H \mid A) & =\frac{P(H) P(A \mid H)}{P(H) P(A \mid H)+P(\bar{H}) P(A \mid \bar{H})}, \\
P(H \mid \bar{A}) & =\frac{P(H) P(\bar{A} \mid H)}{P(H) P(\bar{A} \mid H)+P(\bar{H}) P(\bar{A} \mid \bar{H})} .
\end{aligned}
$$

As can be seen from the above equation, the posterior fault probability is closely related to the prior probability and presents a positive correlation.

(1) Original data: the component failure rate data come mainly from the real-time train safety monitoring system. Assuming a steady-state operating time of $100 \mathrm{~h}$, the details and calculation results are shown in Table 4.

(2) Calculation results 


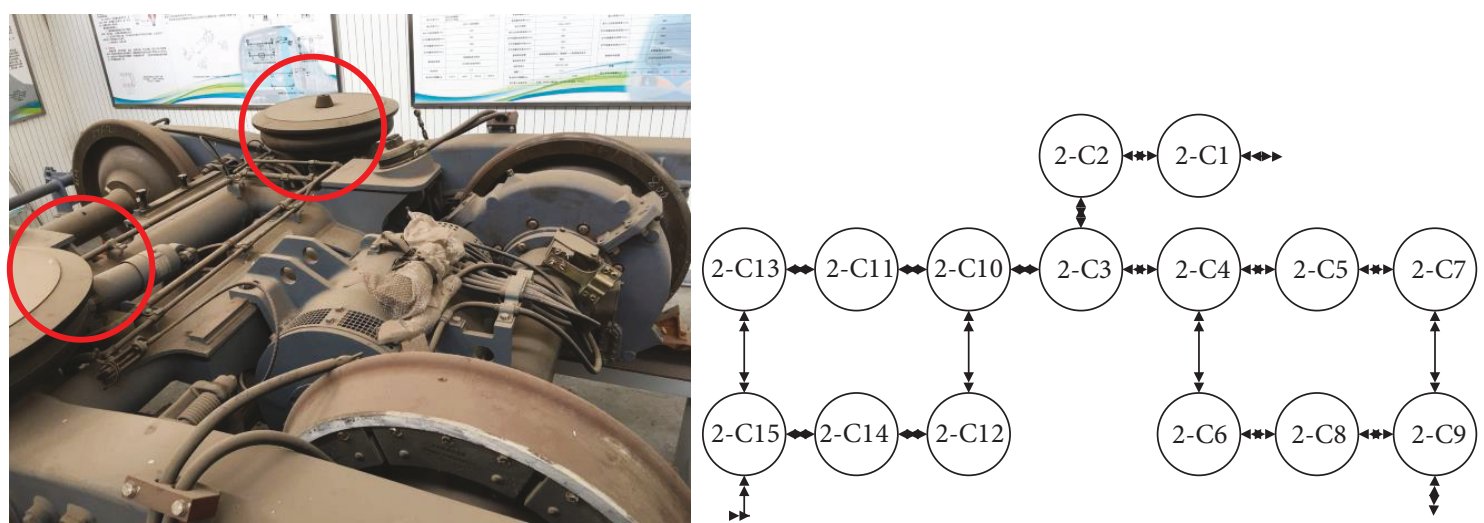

Figure 7: Model of air spring suspension.

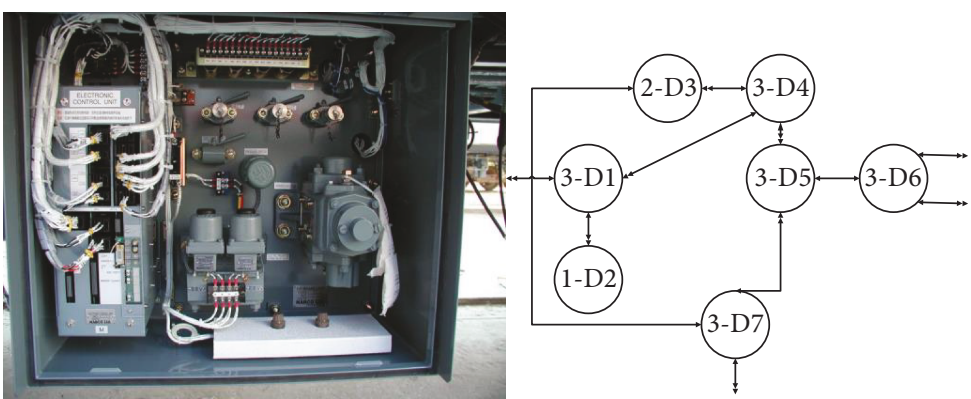

Figure 8: Model of a brake control device.

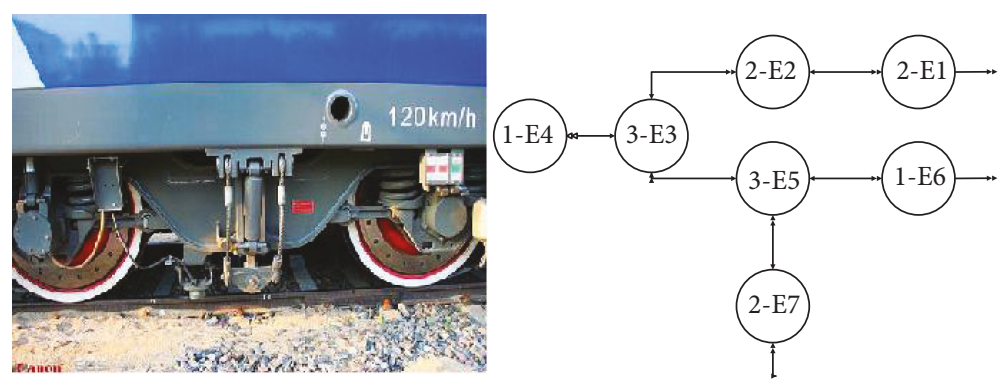

FIgURE 9: Model of parking brake control device.
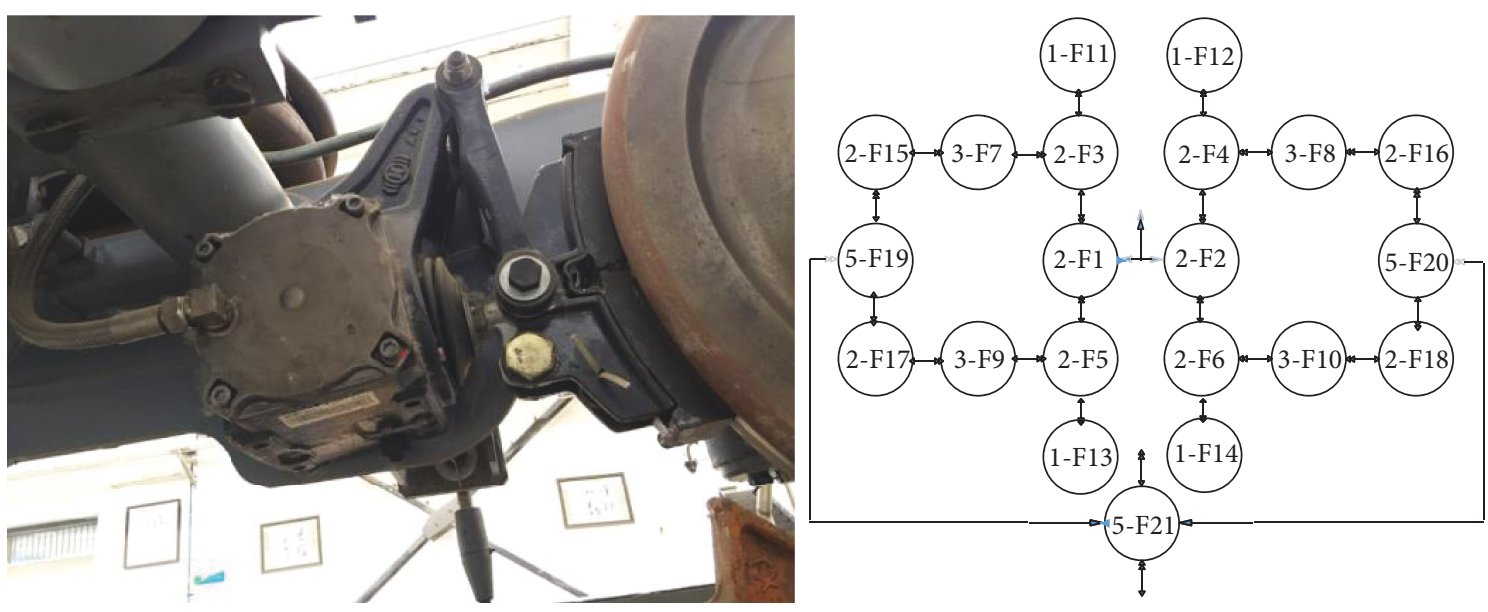

Figure 10: Model of a basic braking device. 


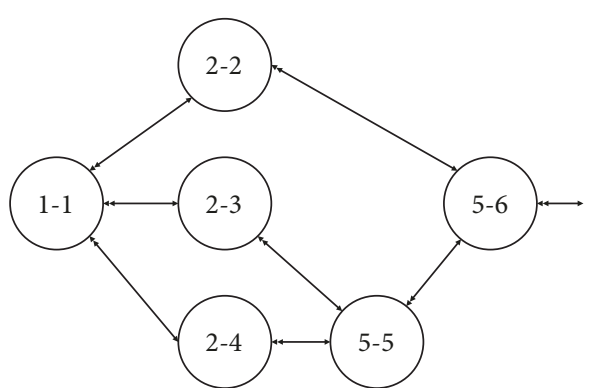

FIGURE 11: System model with a common signal.

3.4. Experimental Analysis. From the above safety analysis, we can draw the following conclusions:

(1) When a system exhibits abnormal behavior, we have to obtain the real-time inverse probability through a fault backward reasoning method. The inverse probabilities of the components (3-B4, 0.01), (1-B5, 0.15), (3-D1, 0.04), (1-D2, 0.78), and (1-F11, 0.47) are significantly larger than those of the other inverse components, which indicates that these parts may be abnormal. We should therefore focus on tracking them. In addition, by using the system diagram model to analyze 3-B4, 1-B5, 3-D1, and 1-D2, which are working parts that are connected together, the abnormal output of 3-D1 indicates that the possibilities of failure of these four components are very large, with that of $(1-\mathrm{D} 2,0.78)$ being the highest. This represents the electronic control unit, which has a higher error rate than other components because of the many electronic circuit elements that it contains. While (1-F11, 0.47) is an independent failure, in fact, it represents the speed sensor with a self-resetting function. False detection of failure occurs frequently for this component. If an abnormal event is detected when its probability of failure is less than $1 / 2$, it should be checked and then repaired if necessary. This is because the failure probability of the equipment is generally not very large. If there is a large probability of failure, it indicates that there is a possibility of error detection or improper operation, so the threshold value of $1 / 2$ is set up

(2) Traditional fault probability calculations, such as FTA, ETs, and HFACS, depend on the forward deduction of historical data. By contrast, the GO-Bayes method provides structural models of a system and an inverse reasoning probability. The model output and inverse probability reflect the system's reliability more accurately than traditional fault probability

The GO method was initially developed to solve reliability problems for complex systems, and the proposed GO-Bayes method combines it with a Bayes approach and considers both normal and reverse probabilities, thus making the method adaptable to a complex system such as a transit braking system.

\section{Big Data Platform of Air Braking System}

The operating data of the braking system is transmitted to the ground equipment, and through the execution of big data mining, the operating status and events in the running process are analyzed. Through GO-Bayes analysis, the fault early warning and hidden trouble investigation of the equipment are finally achieved.

4.1. Big Data System Architecture. As shown in Figure 12, the system consists of five parts: $\log$ download device, wireless transmission device, data operation server, GO-Bayes fusion module, and visualization terminal.

4.2. Key Technologies. The big data platform mainly includes the following key technologies:

(1) Big data storage and processing: the main storage and processing modes can be divided into two kinds of stream processing and batch processing. Stream processing is direct processing. It treats data as a stream. When new data arrives, it is immediately processed and returns the desired result. This mode is suitable for critical events with high real-time requirements: air compressor failure, dry tower leakage, etc. Batch processing is stored before postprocessing. This mode is suitable for parts that do not require high real-time performance

(2) Data mining and fusion: air braking system will generate a large amount of data during operation, such as various status data and equipment maintenance data. Through the mining and fusion of the braking system's operating data, the potential relationship between data can be excavated and the system can be obtained. As a result, we can realize the real-time, continuous, macroprecise grasp of the overall situation of the dynamic system and the accurate perception of local, multiangle, multilayer, and multimode

(3) Data visualization: data visualization technology refers to the use of computer graphics and image processing technology, through the comparison of multidimensional data, mapping through graphics, animation, and other visual means; it is easy to reveal the laws of the data; the correlation between the various factors found abnormal data, etc., while facilitating the understanding of the results of big data analysis

\section{Monte Carlo Simulation of Air Braking System GO-Bayes Method}

Generally speaking, the calculation process of the GO-Bayes method is very complicated and requires significant computational resources. There is thus a high cost in terms of energy and time and a high risk of error when the method is used for sophisticated systems. Therefore, to deal with this issue, a Monte Carlo simulation approach is adopted here to find a numerical solution based on the GO-Bayes 
TABLE 3: Safety analysis results for the braking system.

\begin{tabular}{|c|c|c|c|c|}
\hline Code & $\begin{array}{c}\text { Output unreliability } \\
\text { (cumulative probability of fault) }\end{array}$ & $\begin{array}{c}\text { Output reliability } \\
\text { (normal work probability) }\end{array}$ & $\begin{array}{l}\text { Component input } \\
\text { inverse probability }\end{array}$ & $\begin{array}{c}\text { Component } \\
\text { inverse probability }\end{array}$ \\
\hline $1-\mathrm{A} 1$ & $2.9996 E-04$ & $9.9970 E-01$ & $1.0271 E-02$ & $1.0271 E-02$ \\
\hline $2-\mathrm{A} 2$ & $7.4972 E-04$ & $9.9925 E-01$ & $2.5671 E-02$ & $1.5405 E-02$ \\
\hline $2-\mathrm{A} 3$ & $1.3491 E-03$ & $9.9865 E-01$ & $4.6194 E-02$ & $2.0538 E-02$ \\
\hline $2-\mathrm{A} 4$ & $1.3990 E-03$ & $9.9860 E-01$ & $4.7903 E-02$ & $1.7120 E-03$ \\
\hline $2-\mathrm{B} 1$ & $1.4989 E-03$ & $9.9850 E-01$ & $5.1322 E-02$ & $3.4239 E-03$ \\
\hline $2-B 2$ & $1.6187 E-03$ & $9.9838 E-01$ & $5.5425 E-02$ & $4.1086 E-03$ \\
\hline $2-B 3$ & $1.8683 E-03$ & $9.9813 E-01$ & $6.3970 E-02$ & $8.5591 E-03$ \\
\hline $3-B 4$ & $2.7362 E-03$ & $9.9726 E-01$ & $9.3691 E-02$ & $2.3968 E-03$ \\
\hline 1-B5 & $7.9968 E-04$ & $9.9920 E-01$ & $2.7382 E-02$ & $2.7382 E-02$ \\
\hline $2-\mathrm{C} 1$ & $1.6986 E-03$ & $9.9830 E-01$ & $5.8160 E-02$ & $1.0271 E-02$ \\
\hline $2-\mathrm{C} 2$ & $1.7984 E-03$ & $9.9820 E-01$ & $6.1578 E-02$ & $3.4239 E-03$ \\
\hline $2-\mathrm{C} 3$ & $1.8483 E-03$ & $9.9815 E-01$ & $6.3287 E-02$ & $1.7120 E-03$ \\
\hline 2-C4 & $2.1477 E-03$ & $9.9785 E-01$ & $7.3538 E-02$ & $1.0271 E-02$ \\
\hline $2-\mathrm{C} 5$ & $3.1450 E-03$ & $9.9685 E-01$ & $1.0769 E-01$ & $3.4224 E-02$ \\
\hline 2-C6 & $3.1450 E-03$ & $9.9685 E-01$ & $1.0769 E-01$ & $3.4224 E-02$ \\
\hline 2-C7, 2-C8 & $4.1414 E-03$ & $9.9586 E-01$ & $1.4180 E-01$ & $5.1357 E-03$ \\
\hline 3-C9 & $4.9378 E-03$ & $9.9506 E-01$ & $1.6907 E-01$ & $1.7116 E-02$ \\
\hline $2-\mathrm{C} 10$ & $2.1477 E-03$ & $9.9785 E-01$ & $7.3538 E-02$ & $1.0271 E-02$ \\
\hline 2-C11, 2-C12 & $3.1450 E-03$ & $9.9685 E-01$ & $1.0769 E-01$ & $3.4224 E-02$ \\
\hline 2-C13, 2-C14 & $4.1414 E-03$ & $9.9586 E-01$ & $1.4180 E-01$ & $5.1357 E-03$ \\
\hline $3-\mathrm{C} 15$ & $4.9378 E-03$ & $9.9506 E-01$ & $1.6907 E-01$ & $1.7116 E-02$ \\
\hline 3-D1 & $7.1146 E-03$ & $9.9289 E-01$ & $2.4361 E-01$ & $6.8474 E-03$ \\
\hline 1-D2 & $4.1912 E-03$ & $9.9581 E-01$ & $1.4351 E-01$ & $1.4351 E-01$ \\
\hline 2-D3 & $3.6334 E-03$ & $9.9637 E-01$ & $1.2441 E-01$ & $3.0803 E-02$ \\
\hline $3-\mathrm{D} 4$ & $8.0078 E-03$ & $9.9199 E-01$ & $2.7419 E-01$ & $1.3694 E-02$ \\
\hline 3-D5 & $1.5056 E-02$ & $9.8494 E-01$ & $5.1551 E-01$ & $2.7391 E-03$ \\
\hline 5-D6 & $6.6279 E-03$ & $9.9337 E-01$ & $2.2694 E-01$ & 0 \\
\hline 3-D7 & $1.5252 E-02$ & $9.8475 E-01$ & $5.2226 E-01$ & $6.8474 E-03$ \\
\hline 2-E1 & $3.0354 E-03$ & $9.9696 E-01$ & $1.0393 E-01$ & $1.0271 E-02$ \\
\hline 2-E2 & $3.4341 E-03$ & $9.9657 E-01$ & $1.1759 E-01$ & $1.3694 E-02$ \\
\hline 3-E3 & $3.8824 E-03$ & $9.9612 E-01$ & $1.3294 E-01$ & $1.1982 E-02$ \\
\hline $1-\mathrm{E} 4$ & $9.9995 E-05$ & $9.9990 E-01$ & $3.4239 E-03$ & $3.4239 E-03$ \\
\hline 3-E5 & $1.7367 E-02$ & $9.8263 E-01$ & $5.9467 E-01$ & $1.0271 E-02$ \\
\hline 1-E6 & $1.5942 E-02$ & $9.8406 E-01$ & $5.4585 E-01$ & $2.3960 E-02$ \\
\hline 2-E7 & $1.7485 E-02$ & $9.8251 E-01$ & $5.9871 E-01$ & $4.1086 E-03$ \\
\hline 2-F1,2-F2 & $1.7780 E-02$ & $9.8222 E-01$ & $6.0880 E-01$ & $1.0271 E-02$ \\
\hline 3-F3, 3-F4, 3-F5, 3-F6 & $1.9595 E-02$ & $9.8040 E-01$ & $6.7096 E-01$ & $1.1982 E-02$ \\
\hline 2-F7, 2-F8, 2-F9, 2-F10 & $1.9693 E-02$ & $9.8031 E-01$ & $6.7432 E-01$ & $3.4239 E-03$ \\
\hline 1-F11, 1-F12, 1-F13, 1-F14 & $1.4989 E-03$ & $9.9850 E-01$ & $5.1322 E-02$ & $5.1322 E-02$ \\
\hline 2-F15, 2-F16, 2-F17, 2-F18 & $2.0575 E-02$ & $9.7942 E-01$ & $7.0451 E-01$ & $3.0803 E-02$ \\
\hline 5-F19 & $2.3363 E-02$ & $9.7664 E-01$ & $7.9996 E-01$ & 0 \\
\hline $5-\mathrm{F} 20$ & $2.3363 E-02$ & $9.7664 E-01$ & $7.9996 E-01$ & 0 \\
\hline $5-F 21$ & $2.9205 E-02$ & $9.7079 E-01$ & $1.0000 E+00$ & 0 \\
\hline
\end{tabular}

method. Historical data and current state variations are combined to provide a predictive analysis for future reliability and security.
5.1. Hypothesis Simulation of System Distribution. The failure process is an inherent physical property of the device, and it is a long-term process under steady-state operation, with a 
TABLE 4: Initial data for the basic units in the model from real-time train safety monitoring system.

\begin{tabular}{|c|c|c|c|c|c|}
\hline Code & Failure rate $(10 E-06 / \mathrm{h})$ & Fault rate & Code & Failure rate $(10 E-06 / \mathrm{h})$ & Fault rate \\
\hline $1-\mathrm{A} 1$ & 3 & $2.9996 E-04$ & 3-D5 & 0.8 & $7.9997 E-05$ \\
\hline $2-\mathrm{A} 2$ & 4.5 & $4.4990 E-04$ & 3-D7 & 2 & $1.9998 E-04$ \\
\hline $2-\mathrm{A} 3$ & 6 & $5.9982 E-04$ & 2-E1 & 3 & $2.9996 E-04$ \\
\hline $2-\mathrm{A} 4$ & 0.5 & $4.9999 E-05$ & 2-E2 & 4 & $3.9992 E-04$ \\
\hline 2-B1 & 1 & $9.9995 E-05$ & 3-E3 & 3.5 & $3.4994 E-04$ \\
\hline $2-\mathrm{B} 2$ & 1.2 & $1.1999 E-04$ & 1-E4 & 1 & $9.9995 E-05$ \\
\hline $2-\mathrm{B} 3$ & 2.5 & $2.4997 E-04$ & 3-E5 & 3 & $2.9996 E-04$ \\
\hline $3-\mathrm{B} 4$ & 0.7 & $6.9998 E-05$ & 1-E6 & 7 & $6.9976 E-04$ \\
\hline $1-\mathrm{B} 5$ & 8 & $7.9968 E-04$ & 2-E7 & 1.2 & $1.1999 E-04$ \\
\hline $2-\mathrm{C} 1$ & 3 & $2.9996 E-04$ & $2-\mathrm{F} 1$ & 3 & $2.9996 E-04$ \\
\hline $2-\mathrm{C} 2$ & 1 & $9.9995 E-05$ & $2-\mathrm{F} 2$ & 3 & $2.9996 E-04$ \\
\hline $2-\mathrm{C} 3$ & 0.5 & $4.9999 E-05$ & 3-F3 & 3.5 & $3.4994 E-04$ \\
\hline $2-\mathrm{C} 4$ & 3 & $2.9996 E-04$ & 3-F4 & 3.5 & $3.4994 E-04$ \\
\hline $2-\mathrm{C} 5$ & 10 & $9.9950 E-04$ & 3-F5 & 3.5 & $3.4994 E-04$ \\
\hline 2-C6 & 10 & $9.9950 E-04$ & 3-F6 & 3.5 & $3.4994 E-04$ \\
\hline $2-\mathrm{C} 7$ & 1.5 & $1.4999 E-04$ & 2-F7 & 1 & $9.9995 E-05$ \\
\hline $2-\mathrm{C} 8$ & 1.5 & $1.4999 E-04$ & 2-F8 & 1 & $9.9995 E-05$ \\
\hline 3-C9 & 5 & $4.9988 E-04$ & 2-F9 & 1 & $9.9995 E-05$ \\
\hline $2-\mathrm{C} 10$ & 3 & $2.9996 E-04$ & 2-F10 & 1 & $9.9995 E-05$ \\
\hline $2-\mathrm{C} 11$ & 10 & $9.9950 E-04$ & 1-F11 & 15 & $1.4989 E-03$ \\
\hline 2-C12 & 10 & $9.9950 E-04$ & 1-F12 & 15 & $1.4989 E-03$ \\
\hline 2-C13 & 1.5 & $1.4999 E-04$ & 1-F13 & 15 & $1.4989 E-03$ \\
\hline 2-C14 & 1.5 & $1.4999 E-04$ & 1-F14 & 15 & $1.4989 E-03$ \\
\hline 3-C15 & 5 & $4.9988 E-04$ & 2-F15 & 9 & $8.9960 E-04$ \\
\hline 3-D1 & 2 & $1.9998 E-04$ & $2-\mathrm{F} 16$ & 9 & $8.9960 E-04$ \\
\hline $1-\mathrm{D} 2$ & 42 & $4.1912 E-03$ & 2-F17 & 9 & $8.9960 E-04$ \\
\hline 2-D3 & 9 & $8.9960 E-04$ & $2-\mathrm{F} 18$ & 9 & $8.9960 E-04$ \\
\hline 3-D4 & 4 & $3.9992 E-04$ & & & \\
\hline
\end{tabular}
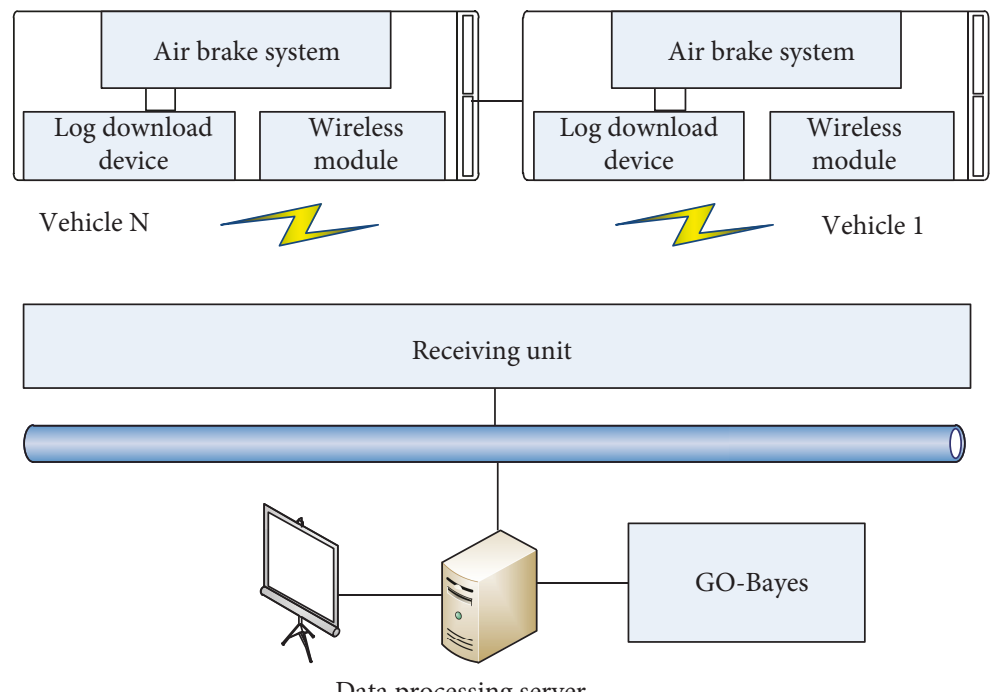

Data processing server

FIgURE 12: Big data system architecture. 
constant failure rate. Such a system is also known as a Markov model repairable system. Its reliability model has an exponential distribution.

There are $n$ components in the system, with each unit and the system as a whole having only two states, normal and faulty, represented by 1 and 0 . The state function is defined as

$$
\Phi(t)= \begin{cases}0, & t \text { time, normal-work state } \\ 1, & t \text { time, abnormal-work state }\end{cases}
$$

$\Phi_{s}(t)$ is the state of the system at time $t$ and $\Phi_{i}(t)$ the state of each part at time $t$.

Based on the analysis of the rail transit braking system using the GO-Bayes model, Monte Carlo simulation is used to check the results of the analytical method described above.

\subsection{Simulation Process}

(1) The first simulation before system failure: for the first simulation before system failure, each component of the system is absolutely new, and the simulation proceeds by examining the security and reliability of the system as time changes. The process is as follows:

(a) The number of simulation is set $N_{\max }$

(b) The maximum system failure time $T_{\max }$ and the number of intervals for the statistics, $k$, are set. The interval length is $\Delta T=T_{\max } / k$. It is assumed that all system failure times are within this interval

(c) Uniform random numbers in the interval $[0,1]$ are generated and converted into a random sample for each unit failure time, i.e., $t_{i}(i=1$, $2, \ldots, n)$

(d) Units in minimal cut sets are obtained by qualitative analysis using the GO-Bayes method, and failure time sample values are $M_{i}(i=1,2$, $3, \ldots, m)$ obtained from the units of each minimal cut set

(e) The failure time of the system is calculated by obtaining the minimum sample value of the failure time of each minimal cut set, i.e., $T_{N}=\min$ $\left\{M_{i}(i=1,2,3, \ldots, m)\right\}$

(f) If $T_{N} \in \Delta T_{j}(j=1,2,3, \ldots, k)$, then the cumulative number is increased by 1 , and the procedure is repeated

(g) The simulation is repeated, and the system failure time is accumulated in each interval until $N_{\max }$, where the simulation ends

The initial failure probabilities are 0 at the first simulation. In the new state, the working times, performance, and tendency are obtained as the time sequence values before the first failure. The system security trends are also evaluated.
(2) Dynamic prediction and simulation of system security status: as changes in the security status of an urban rail transit train braking system occur mainly during operation, fault simulation and forecasting of future operating trends are critical aspects of a system safety study. This process is similar to simulation of the first failure. However, there are some differences: it is necessary to track the servicing time of each unit and confirm its current reliability. In other words, simulation must be done after determining the service time

The simulation process is subject to the following hypotheses:

(a) The reliability state of each unit is steady during the maintenance periods resulting from system failure

(b) Failed parts are removed immediately and repaired offline in the maintenance period. Meanwhile, new parts are installed to keep the system working in a normal state with no effect on its operation

The simulation process is changed on the basis of the simulation of the first failure time, using random samples of unit failure times, as shown in Figure 13, where is the present unit service time and is the remaining service time. The current failure time is sampled to predict the possible service times of the unit in the future.

The related unit service times are shown in Table 5.

We can derive the following results from this experiment, as shown in Figure 14:

(1) The reliability curve before the first failure is the same as the regular probability curve, but they differ from each other after a maintenance and failure update

(2) The trend of the normal probability curve after a system update is worse than before the system's first failure. The reason is that some old units remain in their normal states in the updated system, which will make it easier for the system to get into a failure state. The reliability is also lower

(3) After a system update, the reliability is worse than that of the initial system, although the system can operate as normal. As time goes on, the probability of normal operation is closer to the reliability of the system. It should be noted that reliability is fundamental to safety, while safety provides a reflection of the real-time state of reliability

\section{Conclusions}

From the monitor data of the experiment, the new structural GO-Bayes approach to RAMS presented in this paper is a comprehensive methodology for system safety analysis and evaluation modeling. Using a system diagram model, it is possible to obtain a system's normal work probability output, which is essential for fault backward reasoning. This paper 


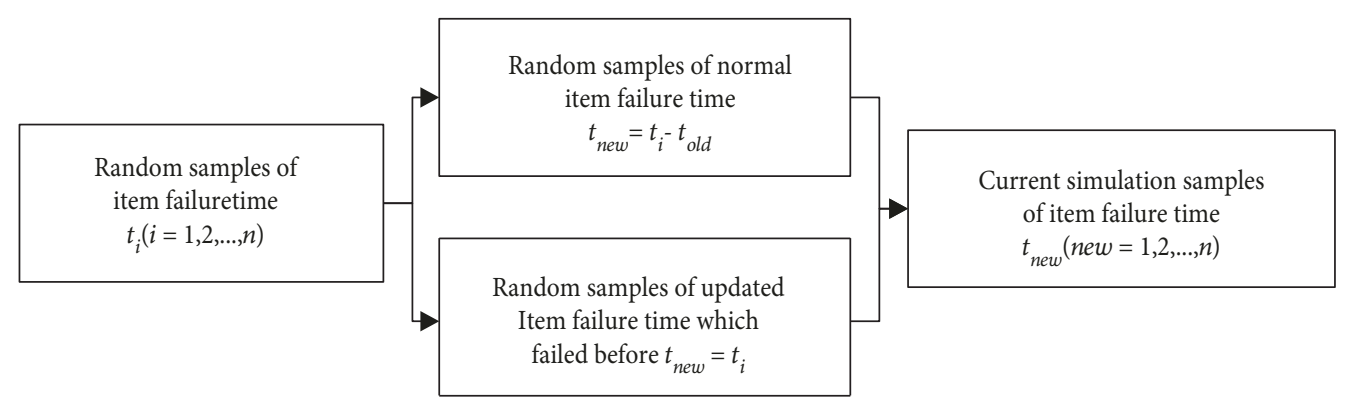

FIGURE 13: Modification of the process of dynamic prediction simulation.

TABLE 5: Related unit service times.

\begin{tabular}{lccccc}
\hline Unit code & $\begin{array}{c}\text { Working } \\
\text { time }\left(t_{\text {old }}\right)\end{array}$ & $\begin{array}{c}\text { Unit } \\
\text { code }\end{array}$ & $\begin{array}{c}\text { Working } \\
\text { time }\left(t_{\text {old }}\right)\end{array}$ & $\begin{array}{c}\text { Unit } \\
\text { code }\end{array}$ & $\begin{array}{c}\text { Working } \\
\text { time }\left(t_{\text {old }}\right)\end{array}$ \\
\hline 1-A1 & 300 & $2-\mathrm{C} 12$ & 500 & $2-\mathrm{F} 3$ & 0 \\
$2-\mathrm{A} 2$ & 300 & $2-\mathrm{C} 13$ & 500 & $2-\mathrm{F} 4$ & 500 \\
$2-\mathrm{A} 3$ & 0 & $2-\mathrm{C} 14$ & 500 & $2-\mathrm{F} 5$ & 500 \\
$2-\mathrm{A} 4$ & 300 & $3-\mathrm{C} 15$ & 500 & $2-\mathrm{F} 6$ & 500 \\
$2-\mathrm{B} 1$ & 500 & $3-\mathrm{D} 1$ & 500 & $3-\mathrm{F} 7$ & 500 \\
$2-\mathrm{B} 2$ & 500 & $1-\mathrm{D} 2$ & 0 & $3-\mathrm{F} 8$ & 500 \\
$2-\mathrm{B} 3$ & 500 & $2-\mathrm{D} 3$ & 500 & $3-\mathrm{F} 9$ & 500 \\
$3-\mathrm{B} 4$ & 500 & $3-\mathrm{D} 4$ & 500 & $3-\mathrm{F} 10$ & 500 \\
$1-\mathrm{B} 5$ & 500 & $3-\mathrm{D} 5$ & 500 & $1-\mathrm{F} 11$ & 0 \\
$2-\mathrm{C} 1$ & 300 & $5-\mathrm{D} 6$ & 0 & $1-\mathrm{F} 12$ & 100 \\
$2-\mathrm{C} 2$ & 500 & $3-\mathrm{D} 7$ & 500 & $1-\mathrm{F} 13$ & 500 \\
$2-\mathrm{C} 3$ & 500 & $2-\mathrm{E} 1$ & 500 & $1-\mathrm{F} 14$ & 500 \\
$2-\mathrm{C} 4$ & 500 & $2-\mathrm{E} 2$ & 500 & $2-\mathrm{F} 15$ & 300 \\
$2-\mathrm{C} 5$ & 500 & $3-\mathrm{E} 3$ & 500 & $2-\mathrm{F} 16$ & 200 \\
$2-\mathrm{C} 6$ & 500 & $1-\mathrm{E} 4$ & 500 & $2-\mathrm{F} 17$ & 500 \\
$2-\mathrm{C} 7$ & 500 & $3-\mathrm{E} 5$ & 100 & $2-\mathrm{F} 18$ & 500 \\
$2-\mathrm{C} 8$ & 500 & $1-\mathrm{E} 6$ & 500 & $5-\mathrm{F} 19$ & \\
$3-\mathrm{C} 9$ & 500 & $2-\mathrm{E} 7$ & 500 & $5-\mathrm{F} 20$ & \\
$2-\mathrm{C} 10$ & 500 & $2-\mathrm{F} 1$ & 500 & $5-\mathrm{F} 21$ & \\
$2-\mathrm{C} 11$ & 500 & $2-\mathrm{F} 2$ & 500 & & \\
\hline & & & & &
\end{tabular}

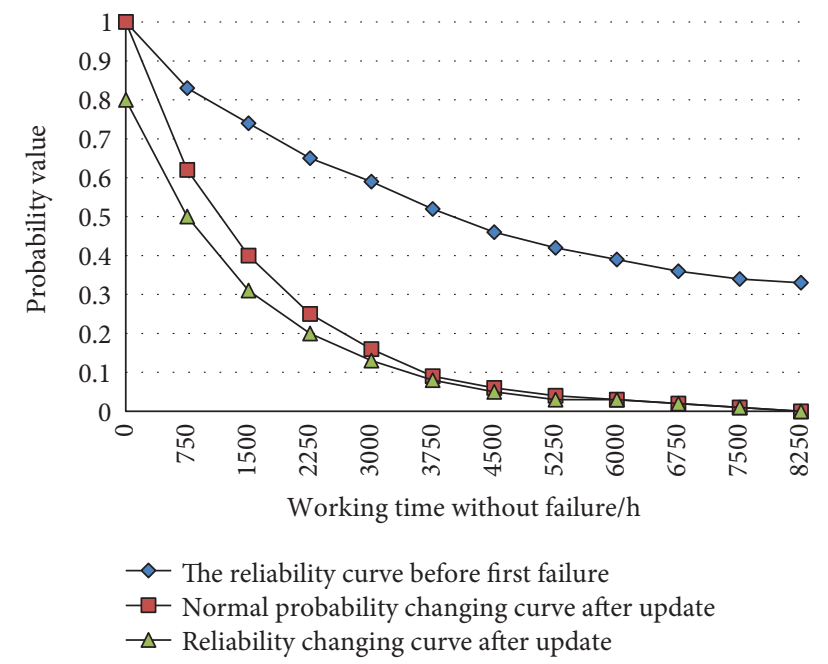

FIGURE 14: Simulation results. has discussed the basic components or units of a system and the related analytical results. Application of the proposed method to a rail transit vehicle air braking system has illustrated its potential contributions to safety analysis and assessment. Finally, it has been shown that the GO-Bayes method provides accurate results consistent with those obtained by a Monte Carlo simulation process and, with progress in simulation techniques, the respective results will become closer. The results can be used to trace, maintain, and improve system components and eventually ensure the safe operation of the system as a whole.

\section{Data Availability}

The data used to support the findings of this study are available from the corresponding author upon request.

\section{Conflicts of Interest}

The authors declare that there are no conflicts of interest regarding the publication of this article.

\section{Acknowledgments}

This work was supported by the China High Technologies Research Program (RCS2017ZJ001 and Z171100002117007).

\section{References}

[1] A. E. Pugel, V. V. Simianu, and D. R. Flum, "Use of the surgical safety checklist to improve communication and reduce complications," Journal of Infection and Public Health, vol. 8, no. 3, pp. 219-225, 2015.

[2] J. B. Long, P. K. Birmingham, and G. S. De Oliveira Jr., "Transversus abdominis plane block in children: a multicenter safety analysis of 1994 cases from the PRAN (pediatric regional anesthesia network) database," Survey of Anesthesiology, vol. 59, no. 3, pp. 139-140, 2015.

[3] R. P. Saunders, S. Wilcox, and M. Baruth, "Process evaluation methods, implementation fidelity results and relationship to physical activity and healthy eating in the faith, activity, and nutrition (FAN) study," Evaluation and Program Planning, vol. 43, pp. 93-102, 2014.

[4] L. Ibánez, J. Hortal, and C. Queral, “Application of the integrated safety assessment methodology to safety margins. Dynamic event trees, damage domains and risk assessment," 
Reliability Engineering \& System Safety, vol. 147, pp. 170-193, 2016.

[5] J. H. Purba, J. Lu, and G. Zhang, "A fuzzy reliability assessment of basic events of fault trees through qualitative data processing," Fuzzy Sets and Systems, vol. 243, pp. 50-69, 2014.

[6] P. S. Appelbaum, P. C. Robbins, and J. Monahan, "Violence and delusions: data from the MacArthur violence risk assessment study," The American Journal of Psychiatry, vol. 157, no. 4, pp. 566-572, 2000.

[7] R. Madigan, D. Golightly, and R. Madders, "Application of human factors analysis and classification system (HFACS) to UK rail safety of the line incidents," Accident; Analysis and Prevention, vol. 97, pp. 122-131, 2016.

[8] IEC62278:2002, Railway Applications: The Specification and Demonstration of Reliability, Availability Maintainability and Safety (RAMS), CENELEC, Genva, Switzerland, 2002.

[9] X. Kang, W. Wang, and J. Liu, "Research on comprehensive evaluation system for track irregularity of high-speed railway based on RAMS," China Railway Science, vol. 34, no. 2, pp. 13-17, 2013.

[10] W. Pu, Management of RAMS in the Integrated and Supervision Control System of Urban Rail Transit, Urban Mass Transit, 2011.

[11] C. L. M. C. Shenzhen, The Introduction of RAMS Management into Urban Rail Transit, Urban Mass Transit, 2007.

[12] Chen Lei MTR Consulting (Shenzhen) Co., Ltd., The Introduction of RAMS Management into Urban Rail Transit, Urban Mass Transit, 2007.

[13] G. F. Cooper and E. Herskovits, "A Bayesian method for the induction of probabilistic networks from data," Machine Learning, vol. 9, no. 4, pp. 309-347, 1992.

[14] C. Dobrivoje, G. Milomir, S. Mile, and D. Jasna, "Fault tree analysis of hydraulic power-steering system," International Journal of Vehicle Design, vol. 64, no. 1, pp. 26-45, 2014.

[15] C. C. Holmes and B. K. Mallick, "Bayesian regression with multivariate linear splines," Journal of the Royal Statistical Society: Series B (Statistical Methodology), vol. 63, no. 1, pp. 3-17, 2001.

[16] S. Sun, Analysis on RAMS of Rail Transit Signal System, 2007, Urban Mass Transit.

[17] K. Yasuoka, A. Watabe, T. Hattori, and M. Matsumoto, "The policy of applying RAMS to evaluate railway signalling systems for reliable transportation," in FORMS/FORMAT 2010, E. Schnieder and G. Tarnai, Eds., pp. 55-63, Springer, Berlin Heidelberg, 2011.

[18] Y. Yang, W. U. Junyong, and X. Zhang, "RAMS evaluation of a bulk power system to a traction power supply system of high-speed railway," Automation of Electric Power Systems, vol. 31, no. 20, pp. 98-102, 2007.

[19] M. W. Chen, "The reliability assessment of traction substation of high speed railway by the GO-methodology," Power System Protection and Control, vol. 39, no. 18, pp. 56-61, 2011.

[20] Z. Shen and J. Gao, "GO methodology and improved quantification of system reliability," Journal of Tsinghua University, vol. 39, no. 6, pp. 15-19, 1999.

[21] Z. P. Shen, G. Jia, and X. Huang, "A new quantification algorithm for the GO methodology," Reliability Engineering and System Safety, vol. 67, no. 3, pp. 241-247, 2000.

[22] Y. Z. Huang, Q. Shi, J. F. Hao, and W. Liang, "Automobile brake system reliability analysis based on GO method," Ordnance Industry Automation, vol. 27, no. 11, pp. 77-78, 2008.
[23] L. Chen and Y. Zhang, Management of RAMS in Chengdu Metro, Urban Mass Transit, 2009.

[24] M. Takkishi and K. Michiyuki, "GO-FLOW: a new reliability analysis methodology," Nuclear Science and Engineering, vol. 98, no. 1, pp. 64-78, 1988.

[25] Z. Feng, L. Li, and S. Wang, "A reliability evaluation of high speed railway overhead contact systems based on the GOFLOW methodology," Transactions of China Electrotechnical Society, vol. 30, no. 12, pp. 351-356, 2015.

[26] G. J. Wu, Y. Wang, Y. L. Shang, and C. Yan, "Reliability analysis of repairable system based on GO-FLOW methodology," Nuclear Power Engineering, vol. 3, no. 5, pp. 282-304, 2012.

[27] L. Liang, F. Zhao, and S. Wang, "A reliability evaluation of high speed railway traction substation based on the GO-FLOW methodology," Telkomnika Indonesian Journal of Electrical Engineering, vol. 12, no. 7, 2014.

[28] Sardar MS Zafar Sand Zahid Z., "Computing topological indices of the line graphs of banana tree graph and firecracker graph," Applied Mathematics and Nonlinear Sciences, vol. 2, no. 1, pp. 83-92, 2017.

[29] D. Yang, Y. Tseng, and T. Wang, “A comparison of geometry problems in middle-grade mathematics textbooks from Taiwan, Singapore, Finland, and the United States," Eurasia Journal of Mathematics Science and Technology Education, vol. 13, pp. 2841-2857, 2017.

[30] D. Li, T. Zhang, W. Zhou, and Y. Haodong, "State-of-the-art and trend analysis of big data application in rail transit," Urban Rapid Rail Transit, vol. 6, 2016.

[31] E. Fumeo, L. Oneto, and D. Anguita, "Condition based maintenance in railway transportation systems based on big data streaming analysis," Procedia Computer Science, vol. 53, no. 1, pp. 437-446, 2015.

[32] F. Ghofrani, Q. He, R. M. P. Goverde, and X. Liu, "Recent applications of big data analytics in railway transportation systems: a survey," Transportation Research Part C Emerging Technologies, vol. 90, pp. 226-246, 2018.

[33] G. U. Weihua, T. Huang, and P. Guo, Big Data Oriented Management of Unstructured Data in Urban Rail Transit, Urban Mass Transit, 2016.

[34] H. W. Wang, T. Y. Shi, H. Jiang, and J. Zhu, "A study on big data platform for monitoring the status of railway transportation equipment," Railway Transport \& Economy, vol. 40, no. 2, pp. 38-43, 2018. 


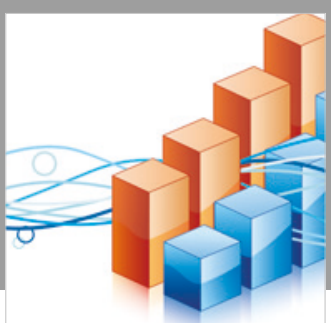

Advances in

Operations Research

\section{-n-m}
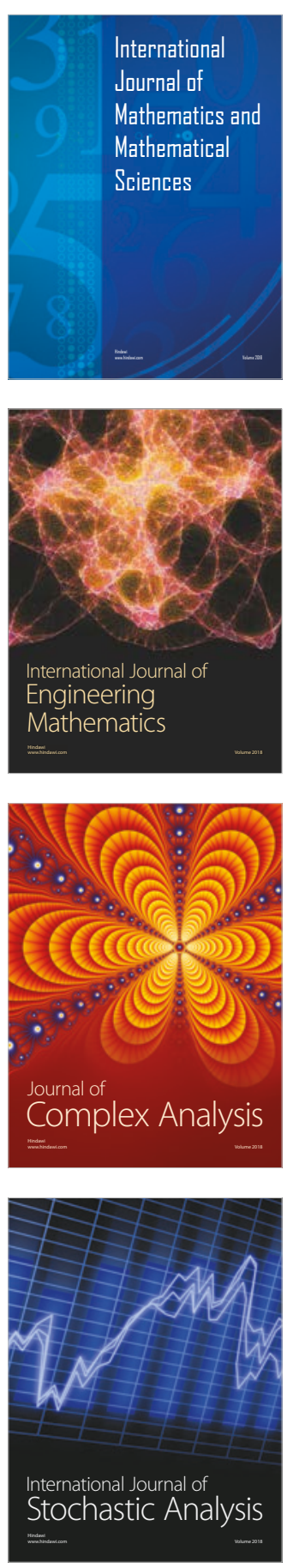
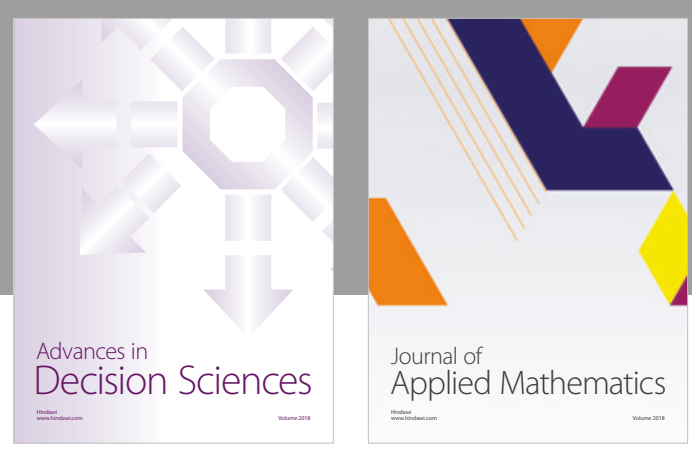

Journal of

Applied Mathematics
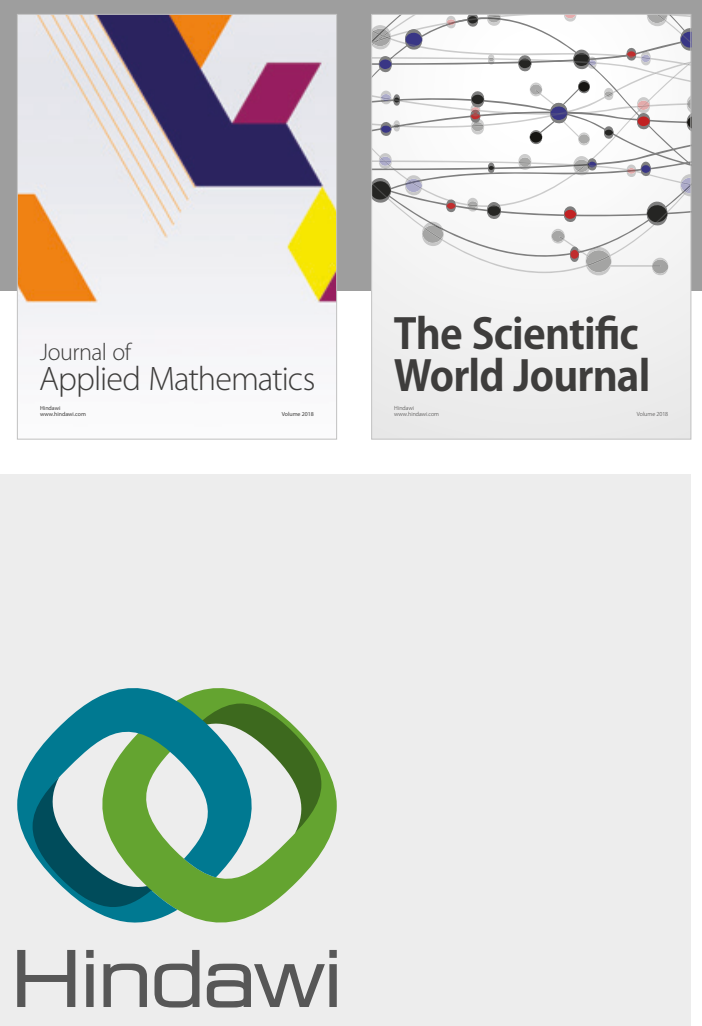

Submit your manuscripts at

www.hindawi.com

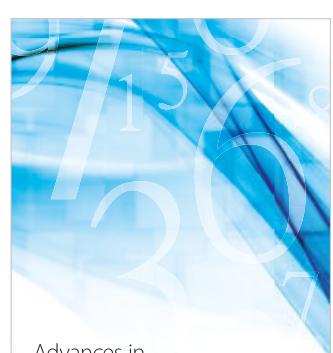

Advances in
Numerical Analysis
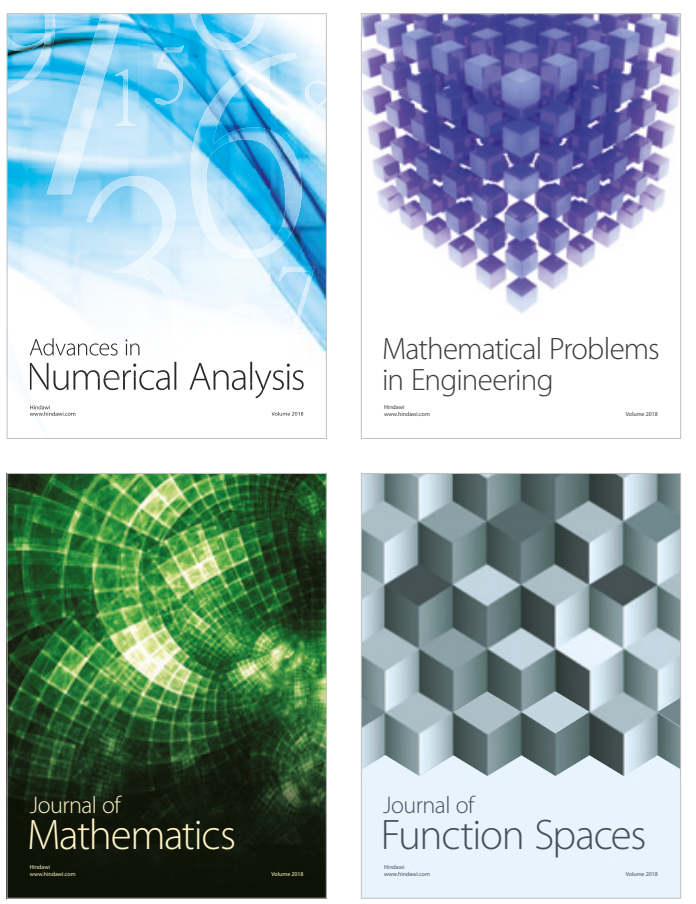

Mathematical Problems in Engineering

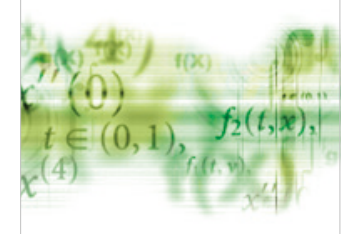

International Journal of

Differential Equations

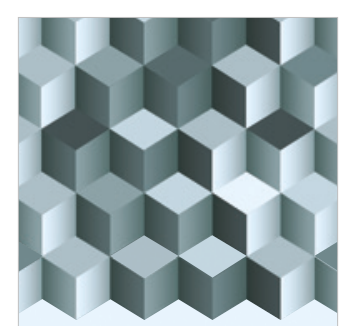

Journal of

Function Spaces
The Scientific

World Journal

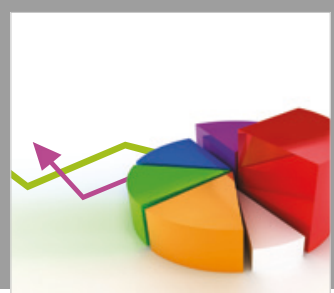

Journal of

Probability and Statistics
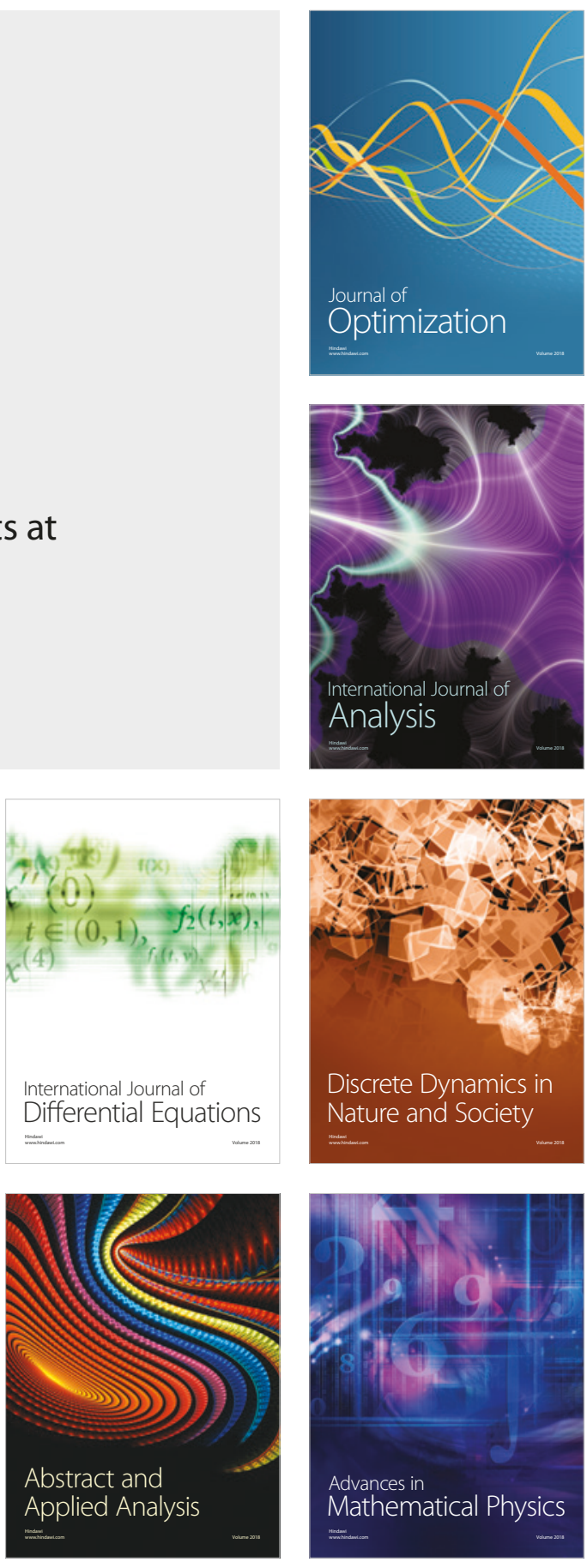